\section{Need for Clinical Guidelines for Management of Osteo- porosis: Do Not Forget Role of Rehabilitation Interventions}

We have read with interest "Need for Clinical Guidelines for Management of Osteoporosis and Way Forward for Pakistan" by Khan and Chandran with interest. ${ }^{1}$ They have correctly highlighted the importance of osteoporosis as a global healthcare issue that needs multiple stakeholders' attention. They have also identified the lack of high-quality data on the burden of osteoporosis in Pakistan as one of the issues that should be addressed. They have pointed out the shortcomings in diagnosing and managing an important bone disorder. The recommendation to have country-specific national guidelines is an apt one. In most of the developing countries, including Pakistan, medical guidelines are usually based or replica of guidelines originating from the West. The drawback is that many of the recommendations are either not culturally feasible or the interventions suggested are either not available or the expertise and infrastructure to implement these guidelines are lacking. Therefore, it is essential that healthcare professionals, based in the developing world, either create their local guidelines or adapt the available ones, considering the available resources, expertise, and healthcare system.

We support the idea of creating country-specific osteoporosis guidelines for Pakistan. However, we suggest that the role of rehabilitation in the prevention and management of osteoporosis must not be overlooked in our country where very little attention is paid to the prevention of diseases and the focus in the management of a disease or medical disorder is usually on pharmacological interventions. The non-drug management options include diet, smoking cessation, exercise and fall-prevention among the elderly. The rehabilitation medicine physicians routinely manage and treat osteoporosis and regularly screen and treat patients for osteoporosis and osteopenia. These include patients with acute and chronic backache, geriatric population, patients with degenerative joint diseases, people with disabilities and pain management, apart from other conditions. Any national guidelines on osteoporosis must highlight the role of rehabilitation in the prevention; and optimal management of osteoporosis and related fractures.

It is important to note that a comprehensive rehabilitation programme for osteoporosis is more than just an exercise prescription. Such a programme is led by rehabilitation medicine physicians (physiatrists) who lead a multi-disciplinary team often consisting of physical therapists, occupa- tional therapists, orthoptists, dieticians, and psychologists. This rehabilitation assessment goes beyond the routine medical and laboratory assessments. Each team member makes individual assessment; and treatment is initiated under the supervision of a rehabilitation medicine physician. A rehabilitation assessment for a person at risk or affected by osteoporosis includes assessment for pain, adequate posture, muscle strength, mobility status, range of motion and flexibility of spine and joints, the risk for falls, balance and the ability to perform daily activities. ${ }^{1}$ Depending upon the severity of the osteoporosis symptoms and disability, a rehabilitation treatment plan may include some or all of the following:

Pain management may include treatment with moist heat, ultrasound, electrical stimulation, vertebroplasty and balloon kyphoplasty.

Educating patient's proper posture and body mechanics.

Encouraging early mobility and prescription of structured exercise programmes for maximising functional recovery.

Teaching a home exercise programme.

Fall-prevention, including exercises for strength, balance retraining and coordination.

Prescription of orthosis and braces for compression fractures ${ }^{2}$ and hip protectors.

Prescribing adaptive equipment for functional independence.

Different forms of exercises are effective in patients with osteoporosis. These include swimming, ${ }^{3}$ pilates, ${ }^{4}$ aquatic exercises ${ }^{5}$ and whole-body vibration training.

We have observed that despite the evidence, the role of rehabilitation in the optimal management of osteoporosis is generally not well understood in Pakistan. The possible reasons include low physician awareness, inadequate referrals, and poor patientcompliance to the rehabilitation plan. We, as rehabilitation professionals, strongly support the idea of national guidelines. However, we suggest that it should include a variety of professionals and must integrate the rehabilitation perspective. This will ensure that patients with osteoporosis in Pakistan can be provided quality service to reduce pain and disability, enhance mobility and improve quality of life.

\section{CONFLICT OF INTEREST:}

The authors declared no conflict of interest.

\section{AUTHORS' CONTRIBUTION:}

FAR: Conceived the idea, performed the literature search and wrote the first draft.

SNM: Performed the literature search, revised the draft for critical input.

Both authors have read and approved the final manuscript for publication 


\section{REFERENCES}

1. Osteoporosis Therapy. Physical Medicine and Rehabilitation. John Hopkins Medicine. Available at Accessed 17th http://www.hopkinsmedicine.org/physical_ medicine_rehabilitation/services/rehab\%20therapy/physical /osteoporosis-therapy.html. April 2021.

2. Meccariello L, Muzii VF, Falzarano G, Medici A, Carta S, Fortina $M$, et al. Dynamic corset versus three-point brace in the treatment of osteoporotic compression fractures of the thoracic and lumbar spine: A prospective, comparative study. Aging Clin Exp Res 2017; 29(3):443-9. doi: 10.1007/ s40520-016-0602-x.

3. Su Y, Chen Z, Xie W. Swimming as treatment for osteoporosis: A systematic review and meta-analysis. Biomed Res Int 2020; 2020:6210201. doi: 10.1155/2020/ 6210201.

4. Angın E, Erden Z, Can F. The effects of clinical pilates exercises on bone mineral density, physical performance and quality of life of women with postmenopausal osteoporosis. J Back Musculoskelet Rehabil 2015; 28(4): 849-58. doi: 10.3233/BMR-150604.
5. Moreira LD, Oliveira ML, Lirani-Galvão AP, Marin-Mio RV, Santos RN, Lazaretti-Castro M. Physical exercise and osteoporosis: Effects of different types of exercises on bone and physical function of postmenopausal women. Arq Bras Endocrinol Metabol 2014; 58(5):514-22. doi: 10.1590/ 0004-2730000003374.

Farooq Azam Rathore ${ }^{1}$ and Sahibzada Nasir Mansoor

${ }_{1}^{1}$ Department of Rehabilitation Medicine, P.N.S. Shifa Hospital, Karachi, Pakistan

${ }^{2}$ Department of Rehabilitation Medicine, AFIRM, Rawalpindi, Pakistan

Correspondence to: Dr. Farooq Azam Rathore, Department of Rehabilitation Medicine, P.N.S. Shifa Hospital, Karachi, Pakistan

E-mail: farooqrathore@gmail.com

Received: April 18, 2021; Revised: June 08, 2021; Accepted: June 18, 2021

DOI: https://doi.org/10.29271/jcpsp.2022.03.412 